\title{
Myopathology of Congenital Myopathies: Bridging the Old and the New
}

Rahul Phadke, MBBS, MD, FRCPath*, ${ }^{+, * *}$

r.phadke@ucl.ac.uk, rahul.phadke@nhs.net

*Dubowitz Neuromuscular Centre, Great Ormond Street Hospital for Children-and Division of Neuropathology, National Hospital for Neurology and Neurosurgery, London, UK

${ }^{\dagger}$ Department of Molecular NeuroscienceNeurodegenerative Disease, UCL-Queen SquareInstitute of Neurology, London, UK

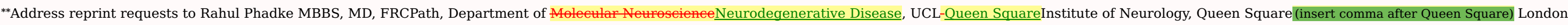
WC1N 3BG, UK.

Disclosure of interests: The author has no commercial, proprietary, or financial interest in any products or companies described in this article.

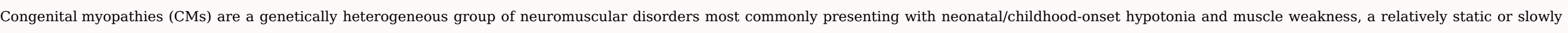

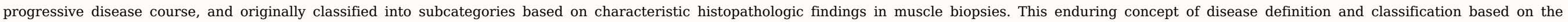

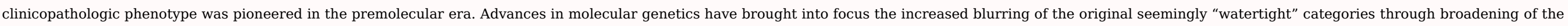

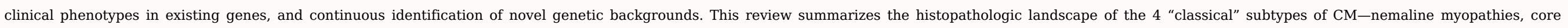
myopathies, centronuclear myopathies, and congenital fiber type disproportion and some of the emerging and novel genetic diseases with a CM presentation.

\section{Introduction}

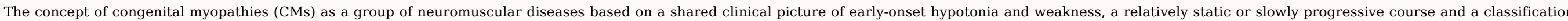

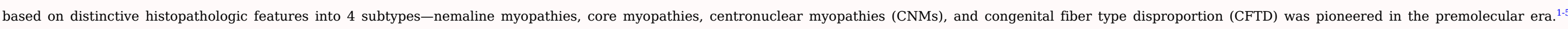

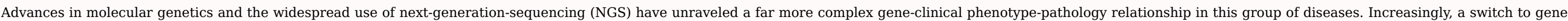

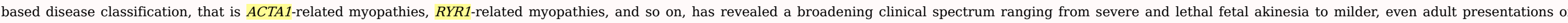

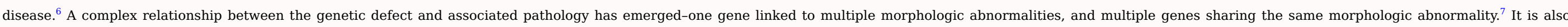

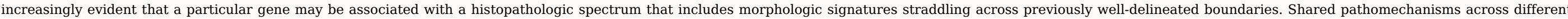

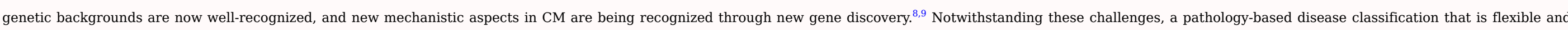

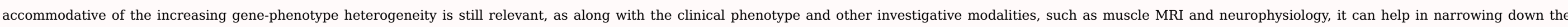
differential diagnosis, in prioritizing genetic testing, and in the interpretation of sequencing results to determine the pathogenicity of genetic variants.

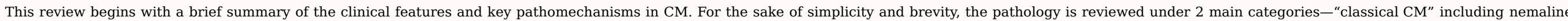

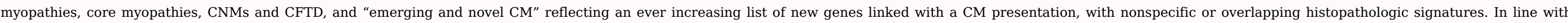

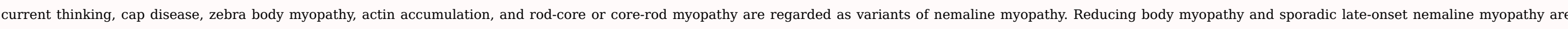

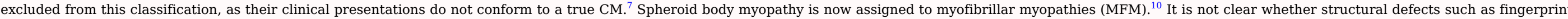

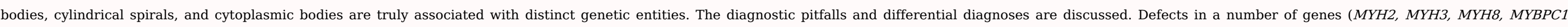
ECEL1, TPM2, TPM3, TNNT2, ACTA1, and NEB) are associated with distal arthrogryposis (DA), with an overlap in many with CM. ${ }^{11}$ These genes mainly associated with DA are not discussed separately.

\section{Clinical Features}

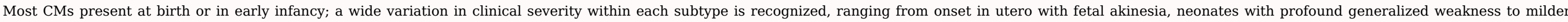




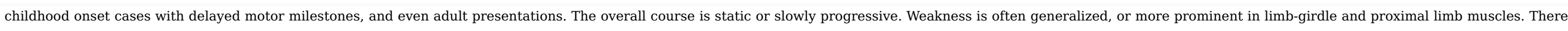

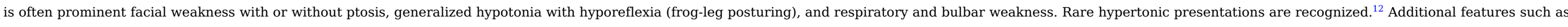

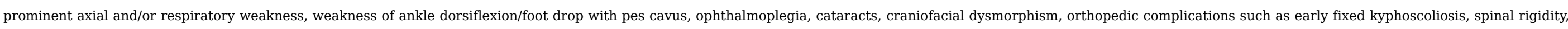

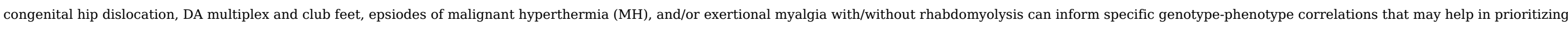

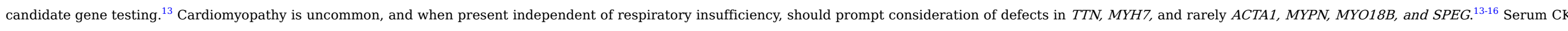

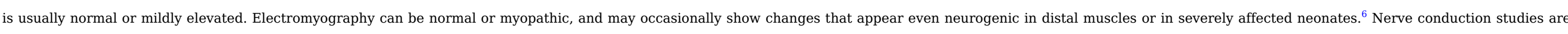

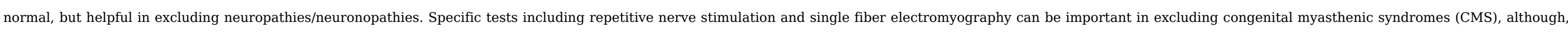

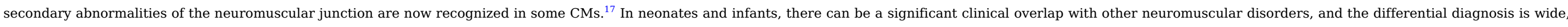
including the congenital muscular dystrophies (CMD), CMS, metabolic/mitochondrial myopathies, spinal muscular atrophy, and Prader-Willi syndrome, all of whom can have a "floppy infant" presentation. ${ }^{6}$

\section{Pathomechanisms}

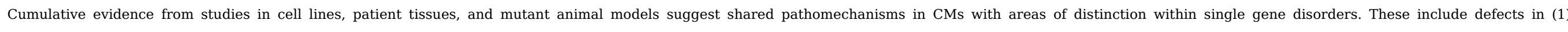

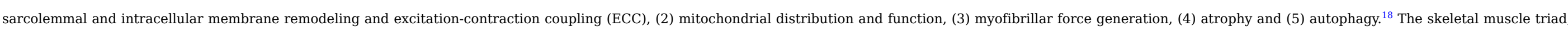

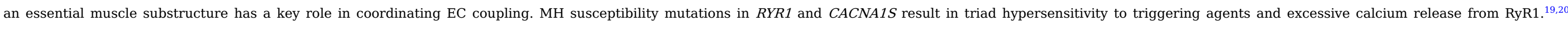

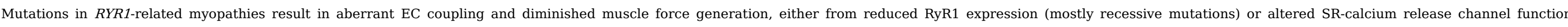

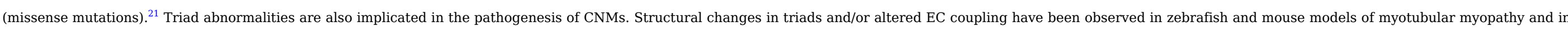

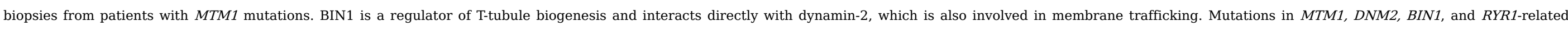

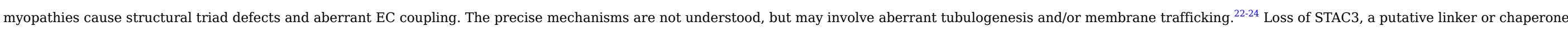

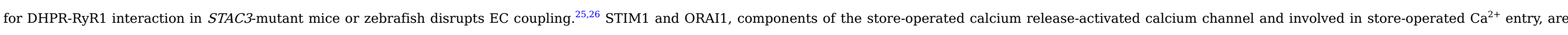

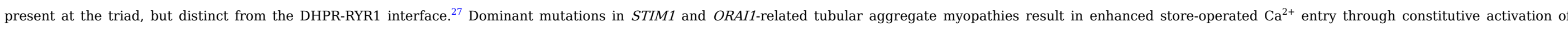

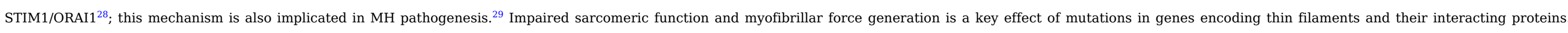

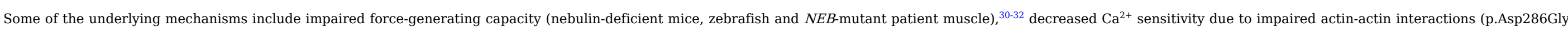

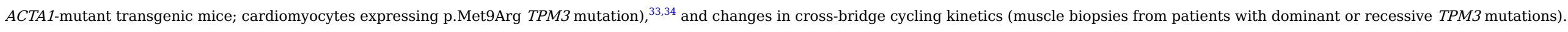

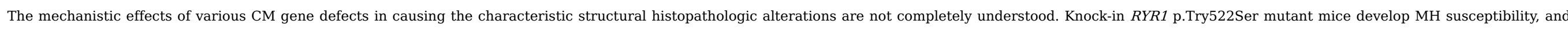

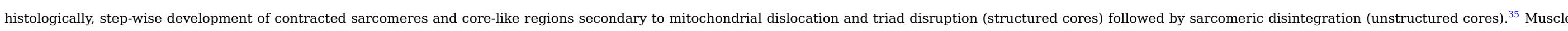

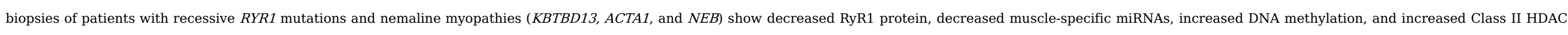
(histone deacetylases) expression indicating shared epigenetic changes may activate a common pathophysiological pathway in some forms of $\mathrm{CM}^{36}$

\section{General Pathologic Features}

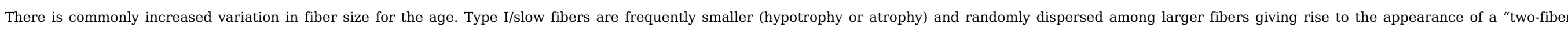

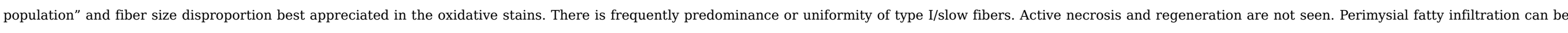

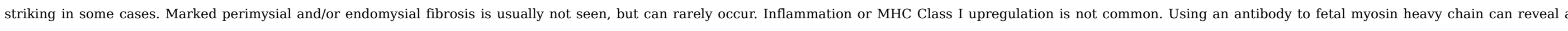

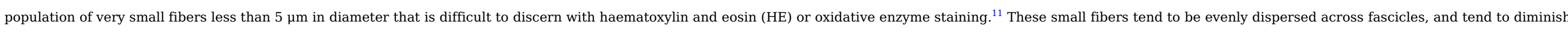

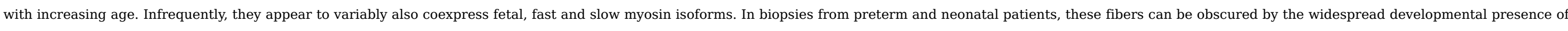

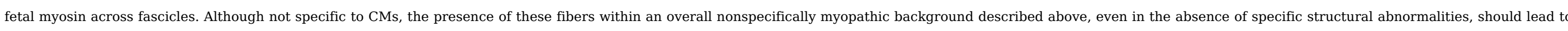

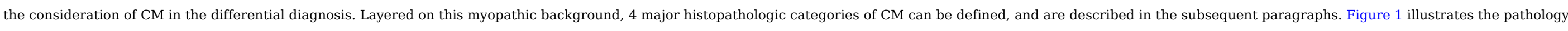
and Table summarizes the pathologic spectrum and protein abnormalities associated with specific genes. 


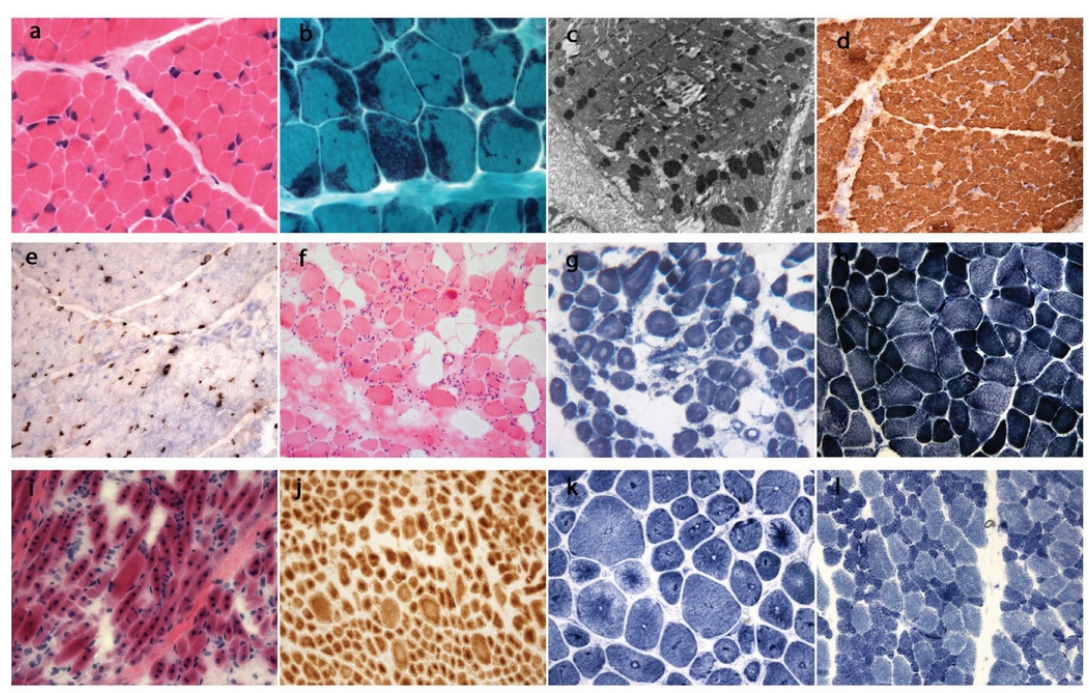

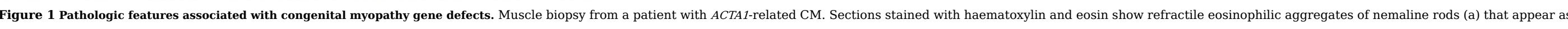

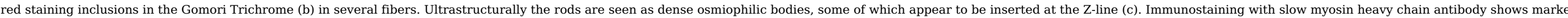

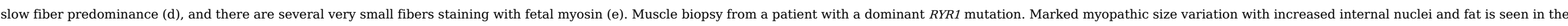

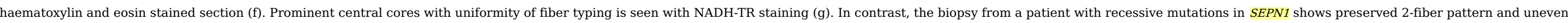

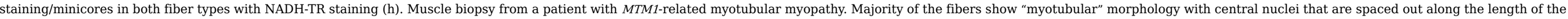

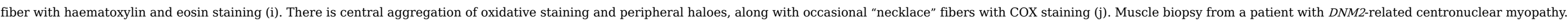

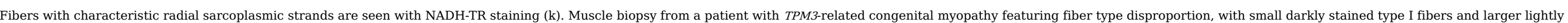
stained type II fibers with NADH-TR staining (l). (Color version of figure is available online.)

alt-text: Figure 1

Table Spectrum of Pathologic Features and Protein Abnormalities Associated With Specific Congenital Myopathy Genes alt-text: Table

\begin{tabular}{|c|c|c|c|c|}
\hline Gene & Protein & Inheritance & Pathologic Spectrum & Protein Abnormality IHC/IB $\dagger$ \\
\hline \multicolumn{5}{|c|}{ Nemaline myopathies } \\
\hline ACTA1 & Filamentous $\alpha$-actin & $\mathrm{AD} \neq, \mathrm{AR}^{0}$ & $\begin{array}{l}\text { Rods in both fibre types; intranuclear rods; actin filament aggregates; caps/cap-like structures; } \\
\text { zebra bodies; rods and cores }\end{array}$ & $\begin{array}{l}\text { Rare homozygous null ACTA1 mutations show complete } \\
\text { absence of filamentous } \alpha \text {-actin and uniform increased } \\
\text { expression cardiac actin }\end{array}$ \\
\hline$N E B$ & Nebulin & AR & Rods in both fiber types; rare cases show cap/cap-like lesions or rods and cores & $\begin{array}{l}\text { Absent immunostaining for the nebulin SH3 domain-specific } \\
\text { antibody in some severe neonatal cases }\end{array}$ \\
\hline TPM2 & $\beta$-tropomyosin & $\mathrm{AD}$ & Rods in both fiber types; caps & - \\
\hline TPM3 & $\alpha$-tropomyosin (slow) & $\mathrm{AD}, \mathrm{AR}$ & Rods restricted to slow fibers; caps & - \\
\hline TNNT1 & Troponin $\mathrm{T}$ (slow) & AR & Rods in both fiber types; severe fibrosis in some cases & $\begin{array}{l}\text { Complete absence of the full length and mutant truncated } \\
\text { slow skeletal Troponin T in Amish type nemaline myopathy } \\
\text { due to homozygous nonsense truncating mutations }\end{array}$ \\
\hline KBTBD13 & $\begin{array}{l}\text { Kelch repeat and } \\
\text { BTB (POZ) domain }\end{array}$ & $\mathrm{AD}$ & Rods in both fiber types; rods and cores & - \\
\hline
\end{tabular}




\begin{tabular}{|l|l|l|}
\hline KLHL4O & $\begin{array}{l}\text { Kelch-like family } \\
\text { member 40 }\end{array}$ & AR \\
\hline KLHL41 & $\begin{array}{l}\text { Kelch-like family } \\
\text { member 41 }\end{array}$ & AR \\
\hline LMOD3 & Leiomodin 3 & AR \\
\hline CFL2 & Cofilin 2 & AR \\
\hline MYPN & Myopallidin & AR \\
\hline MYO18B & Myosin XVIIIB & AR \\
\hline
\end{tabular}

Small nemaline rods

Numerous very small rods sometimes visible only ultrastructurally; few myofibrils in some fibers with many rods; square-shaped/rectangular rods

Rods in both fiber types

Rods in both fiber types; square-shaped/rectangular rods with a fringe

Rods in both fiber types; actin filament aggregates

Slow fiber predominance; cytoplasmic and intranuclear rods

\section{Core myopathies}

\section{RYR1}

SEPN1

MYH7

\section{MYH2}

MEGF10

Ryanodine receptor

$A D, A R$

Selenoprotein N

AR

Slow/ $\beta$-cardiac myosin heavy chain

$\mathrm{AD}$

Fast IIa myosin

heavy chain

$\mathrm{AD}, \mathrm{AR}$

Multiple epidermal

growth factor-like

domains 10

CFL2 Cofilin 2

\begin{tabular}{l|l} 
TTN & Titin
\end{tabular}

Titin

AR

$\mathrm{AD}$

ACTA1 Filamentous $\alpha$-actin

Centronuclear myopathies

\begin{tabular}{l|l} 
MTM1 Myotubularin &
\end{tabular}

X-linked

\section{$D N M 2$}

Dynamin 2

$\mathrm{AD}$

BIN1

\begin{tabular}{l|l} 
Bridging integrator 1 AR & A
\end{tabular}

MYMR14

Myotubularin-related Possible protein 14 Possible
association
Ryanodine receptor
AR
Central cores most closely associated with AD C-terminal mutations; minicores with indistinct fiber typing more frequently associated with recessive mutations, and more frequent noncore pathologies

minicores with cores in both fiber types; slow fiber predominance; nonspecific changes

Both central cores and minicores in Laing distal myopathy; noncore pathologies

Minicores; slow fiber predominance; loss of fast IIa fibers; dystrophic-like changes with advanced disease

Dystrophic-like changes in cases with recessive null mutations; minicores in cases with recessive missense mutations

Minicores; slow fiber predominance; rods (see above)

Minicores in cases with recessive truncating mutations with or without cardiomyopathy or structural cardiac defects; noncore pathology

Rare "cores only" cases

Central nuclei with characteristic "myotubular" pathology; identical morphology in cases of congenital myotonic dystrophy; slow fiber predominance in myotubular myopathy; carrier females, mild phenotype and older biopsies may show internal $>>$ central nuclei, more frequent necklace fibers and "myotubular" features may be absent

Central nuclei, in chains in some fibers; fibers with radiating sarcoplasmic strands-may be absent in younger biopsies; atypical necklace fibers in some cases

Large clustered central nuclei, in chains in some fibers; perinuclear zone of increased oxidative staining

Increased central nuclei

Commonly associated with recessive cases; multiple internal nuclei $>>$ strictly central nuclei
Decreased myopallidin levels detectable in sections immunostained with anti-MYPN antibody; undetectable full length MYPN on immunoblots of transdifferentiated myotubes from patients with recessive mutations

Mutant truncated protein with loss of C-terminus detectable in immunoblots and in sections with antibody against Cterminal MYO18B protein in one case with homozygous recessive truncating mutations

Marked reduction of functional RyR1 protein in recessive cases; secondary reduction in other $\mathrm{CM}$

Marked reduction or absence of $M Y H 2$ transcripts and protein

Total loss of detectable MEGF10 expression in cases with recessive null mutations

Reduced sarcomeric immunostaining for cofilin-2

Loss of staining with C-terminal antibodies in sections and reduction or absence of C-terminal titin fragments on blots; secondary reduction or absence of calpain-3 in C-terminal titinopathies

Absence of endogenous protein detectable on

immunoprecipitation/immunoblot analysis; absence of nuclear foci of muscle blind-like 1 in MTM1-relance of

(

Reduced levels of RyR1 protein (see above) 


\section{$T T N$}

SPEG

Striated muscle

preferentially

expressed protein

CCDC78 containing protein
78 78
Coiled-coil domain-
Commonly associated with recessive cases; multiple internal nuclei $>>$ strictly central nuclei

Marked central nucleation; slow fiber predominance; a few necklace fibers,

Increased central nuclei, slow fiber predominance, core-like areas and sarcoplasmic aggregates

Congenital fiber type disproportion (CFTD)

\begin{tabular}{|l|l|l}
$R Y R 1$ & Ryanodine receptor & AR \\
1 & Selenoprotein & \\
\hline
\end{tabular}

\begin{tabular}{l|l|l} 
SEPN1 & Selenoprotein N & AR
\end{tabular}

\begin{tabular}{l|l|l} 
ACTA1 & Filamentous $\alpha$-actin & $\mathrm{AD}$
\end{tabular}

\begin{tabular}{l|l|l} 
TPM2 & $\beta$-tropomyosin & $\mathrm{AD}$
\end{tabular}

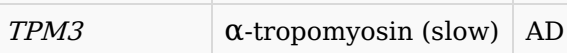

MYH7

Slow/ß-cardiac AD

myosin heavy chain

Emerging or novel genes skeletal muscle dihydropyridineunit

SCN4A Sodium channel, voltage-gated, type IV, $\alpha$ sub-unit

STAC3 SH3 and cysteinerich domains 3

\begin{tabular}{l|l} 
MYBPC3 & Myosin-binding
\end{tabular} protein 3

\begin{tabular}{l|l} 
ZAK & Leucine zipper-and
\end{tabular} sterile $\alpha$-motif

\begin{tabular}{l|l} 
SRPK3 & $\begin{array}{l}\text { Protein kinase, } \\
\text { serine/arginine- }\end{array}$
\end{tabular} serine/arginin
specific, 3

PTPLA/HACD1 3-hydroxacyl-CoA dehydratase 1 containing kinase
CFTD may be the only pattern in some cases

CFTD may be the only pattern in some cases

CFTD may be the only pattern in some cases

CFTD may be the only or predominant feature

CFTD alone is the most frequent pattern

CFTD may be the only pattern in cases

$\mathrm{AD}, \mathrm{AR}$

Slow fiber predominance; increased central/internal nuclei; core-like areas to more severe dystrophic-like features with mildly increased fibrosis; scattered regenerating /necrotic fibers

AR

Dystrophic-like fibrofatty infiltration with fast fiber predominance in fetal akinesia cases; slow fiber hypotrophy; mild slow predominance without specific structural alterations in the CM cases

AR $\quad$ Mild myopathic features, mild slow fiber predominance and hypotrophy in infants; increased central nuclei in an adult

AR $\quad$ Single case with unexpected skeletal myopathy; slow fiber hypotrophy; focal myofibrillar disarray and partial loss of thick filaments on EM

Increased central nuclei; peripheral mitochondrial accumulation, slow fiber predominance; atrophic fibers of both types; rimmed vacuoles in some cases

X-linked

SRPK3-null mice develop type II fiber specific centronuclear myopathy

AR

\section{Centronuclear myopathy in French Labrador retrievers; slow fiber predominance and fiber size} disproportion in biopsies from patients with mild CM

Reduced or absent C-terminal titin (see above)

Marked reduction or absence of SPEG protein on immunoblots and with immunofluorescence studies

Sarcoplasmic aggregates immunoreactive for desmin, and actin; accumulation of CCDC78 and RyR1 within aggregates

Decreased protein levels demonstrable in extracts of cultured myotubes on immunoblots and immunostaining in

Reduced stability and expression of DHPR $\alpha$ seen in zebrafish STAC3 mutants

Aberrant expression of cardiac MYBPC3 transcripts and protein, the latter restricted to small fibers expressing slow/ $\beta$-cardiac myosin heavy chain

ADł: autosomal dominant; $\mathrm{AR}^{0}$ : autosomal recessive; IHC/IB†: immunohistochemistry/immunoblot

\section{Nemaline Myopathies}

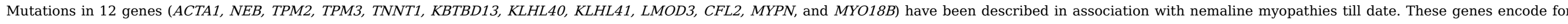




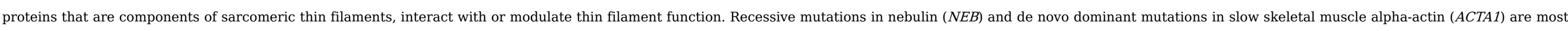

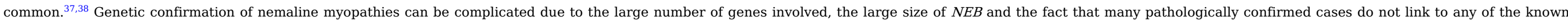

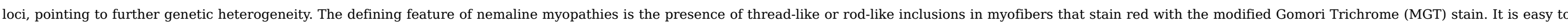

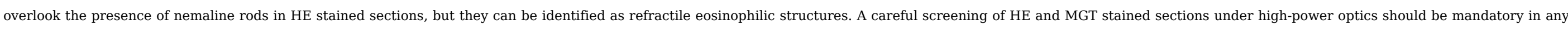

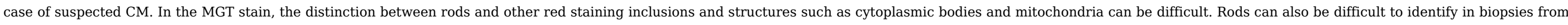

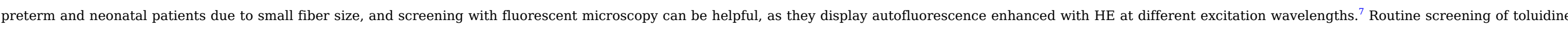

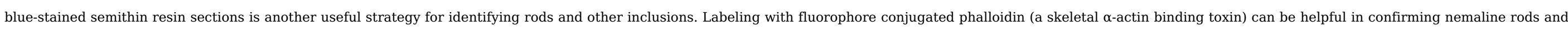

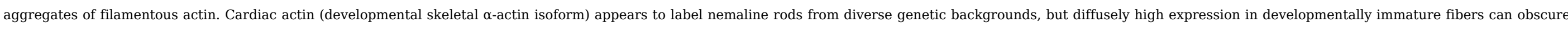

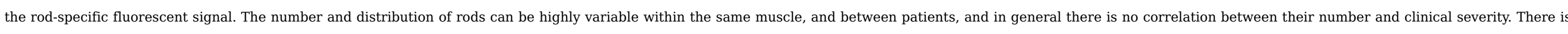

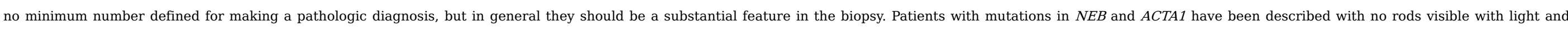

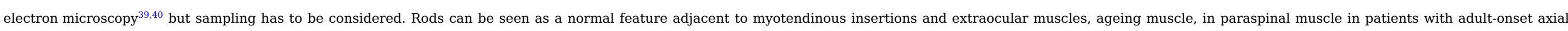

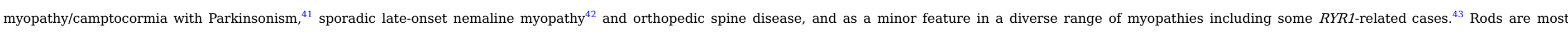

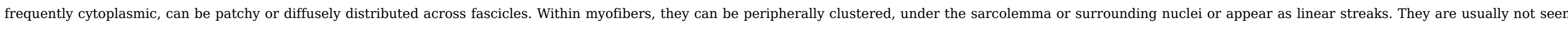

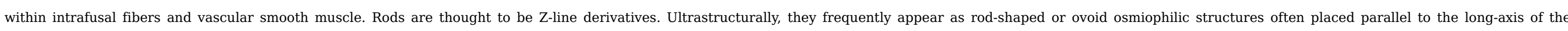

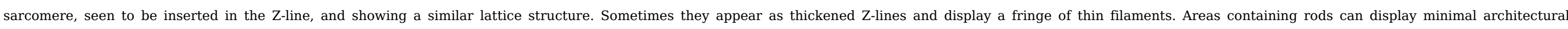

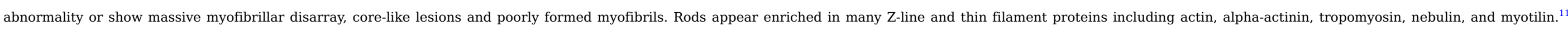

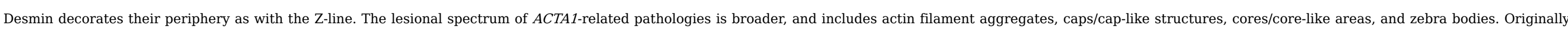

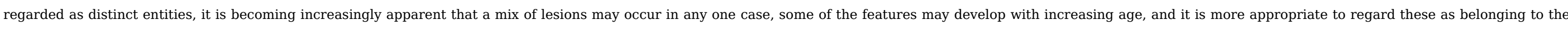

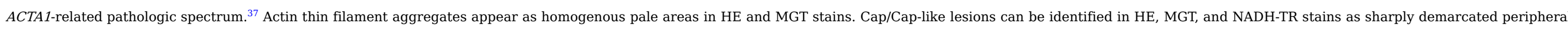

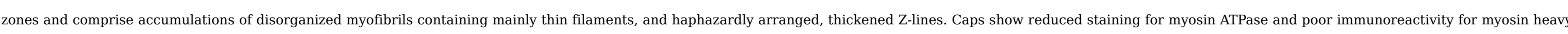

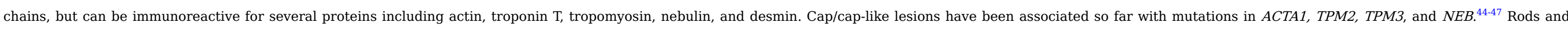

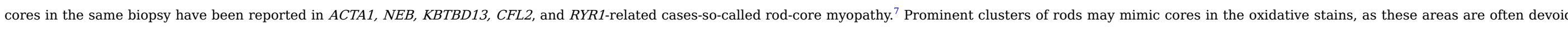

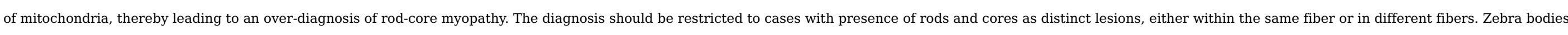
are now considered to be part of the ACTA1-related spectrum. ${ }^{48}$

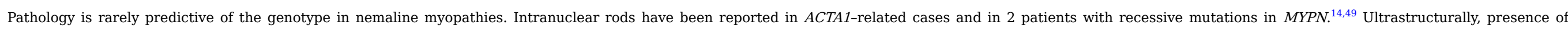

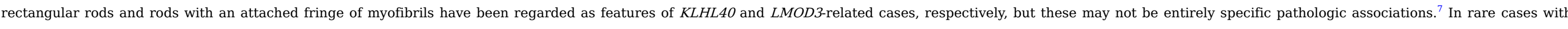

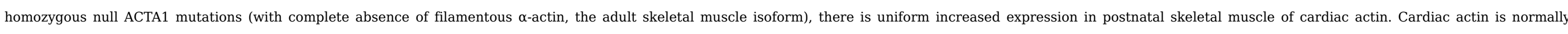

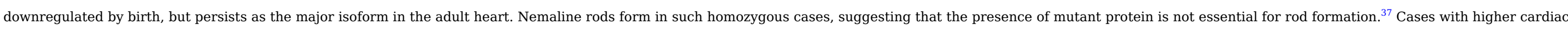

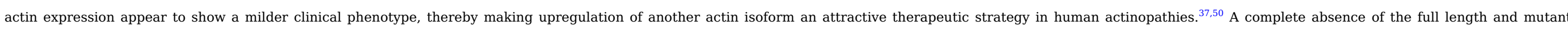

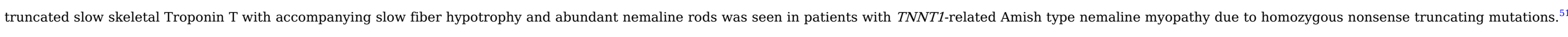

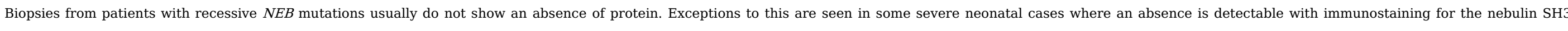

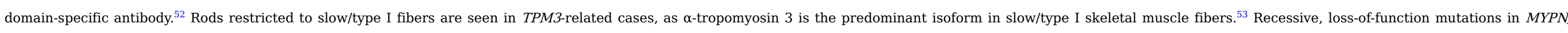

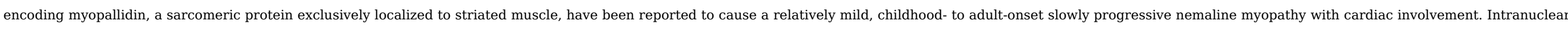

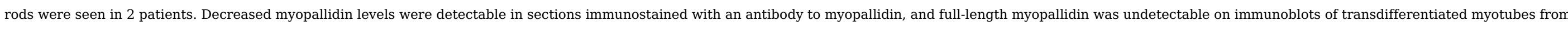

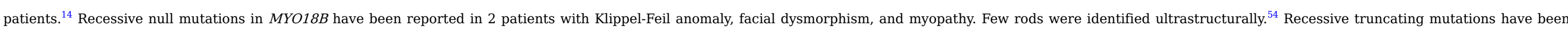

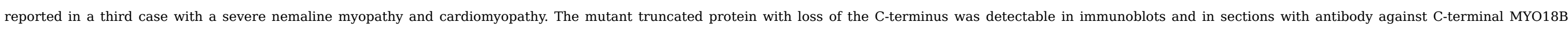
protein..$^{15}$ 


\section{Core Myopathies}

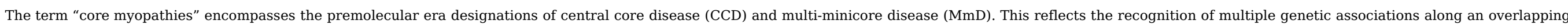

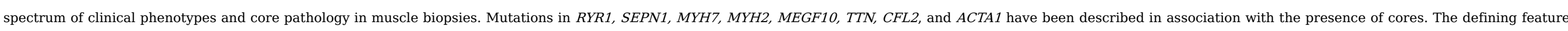

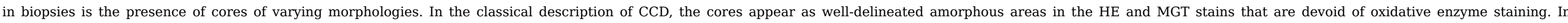

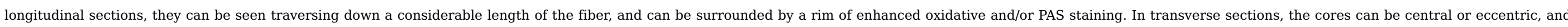

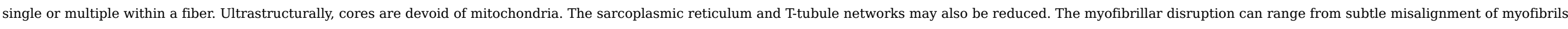

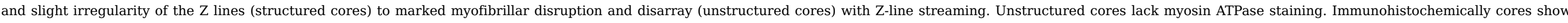

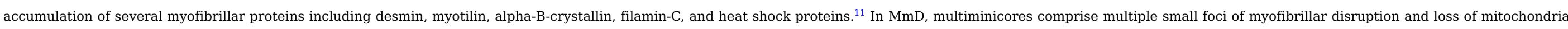

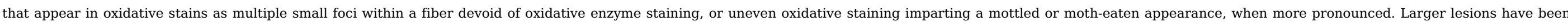

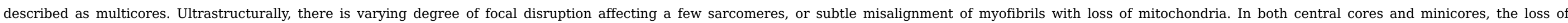
mitochondria can extend beyond the boundaries of the lesion.

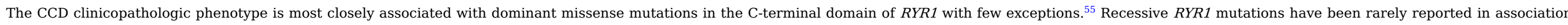

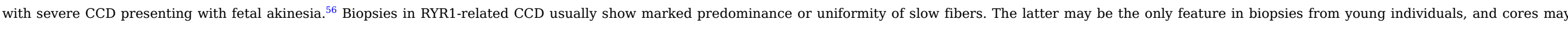

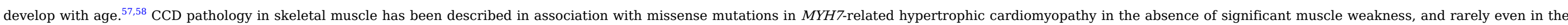

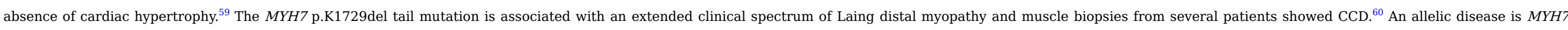

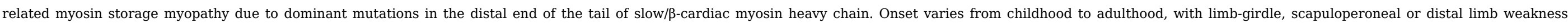

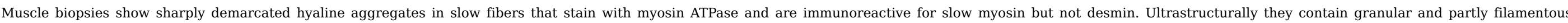

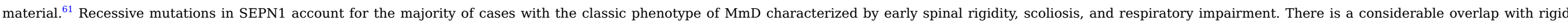

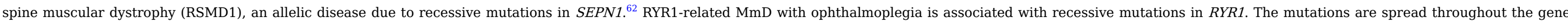

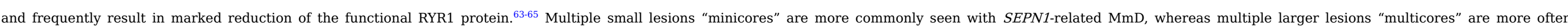

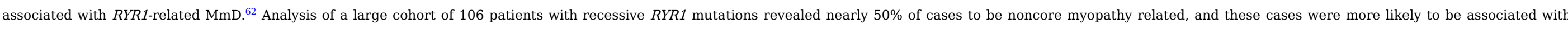

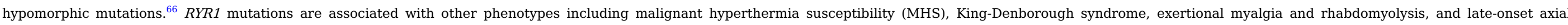

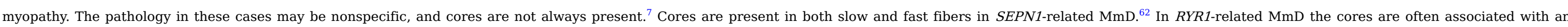

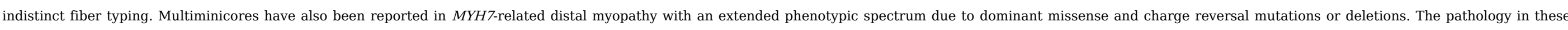

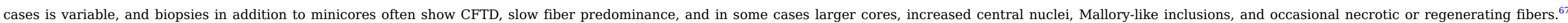

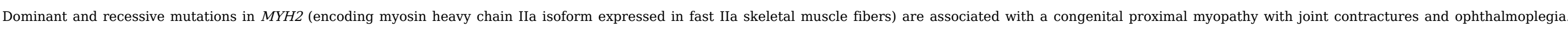

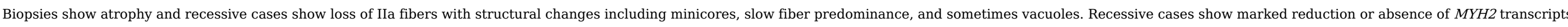

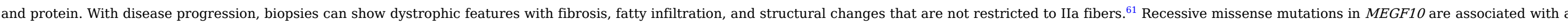

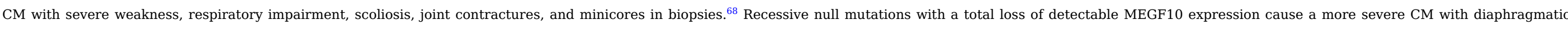

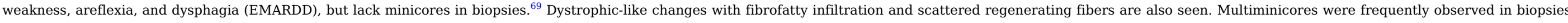

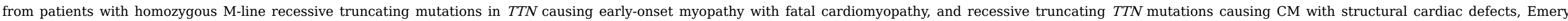

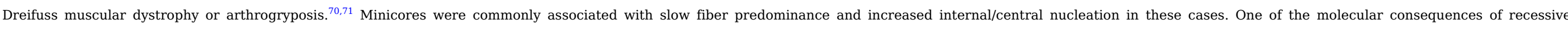

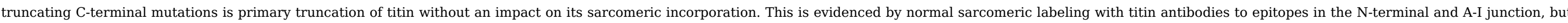

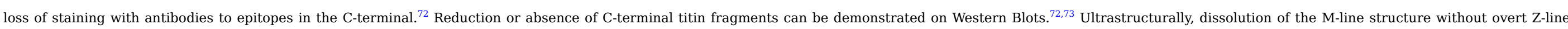

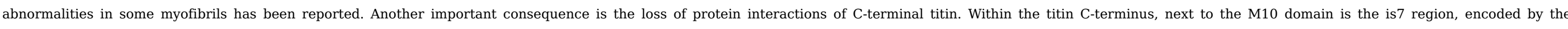

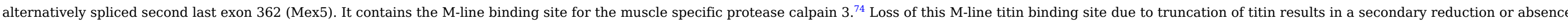

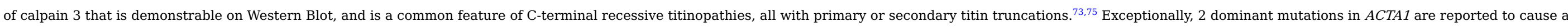




\section{Centronuclear Myopathies}

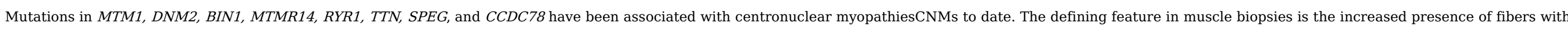

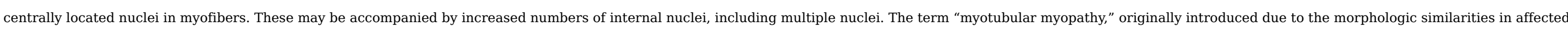

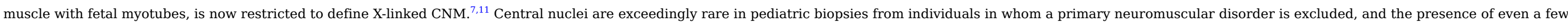

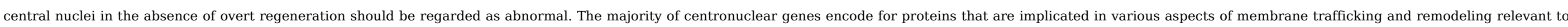
endocytosis, vesicle transport, autophagy, nuclear localization, cell signaling, triad function, and other essential cellular processes.

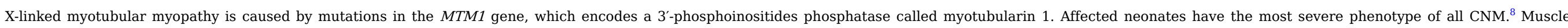

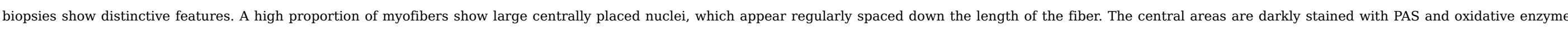

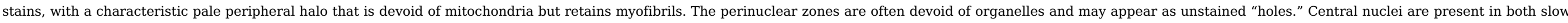

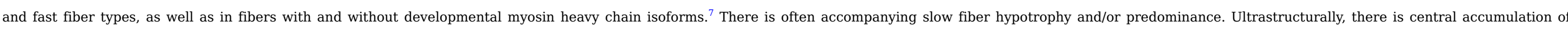

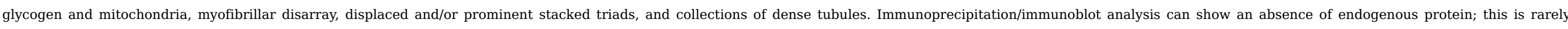

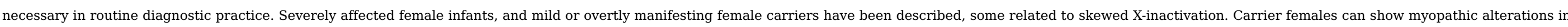

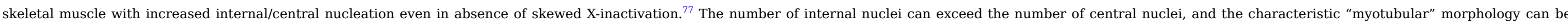

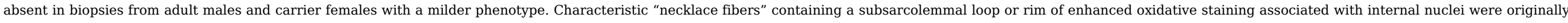

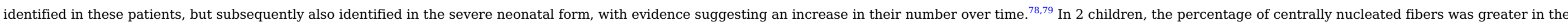

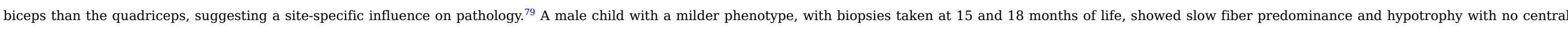

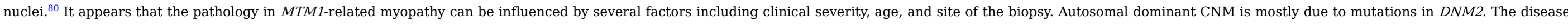

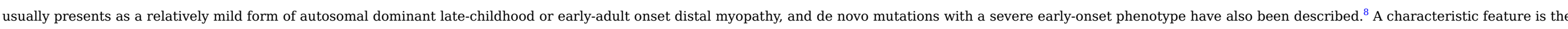

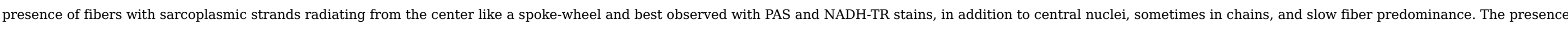

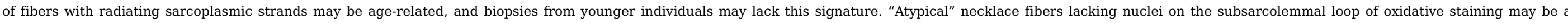

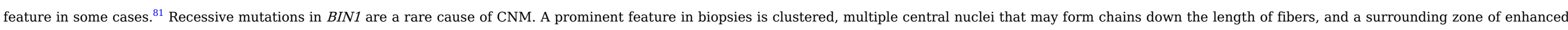

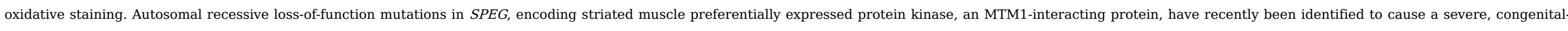

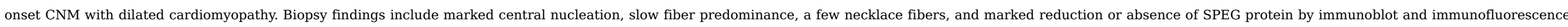

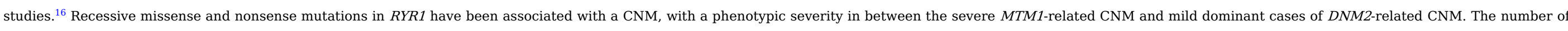

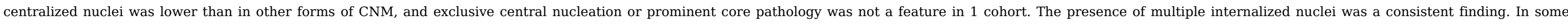

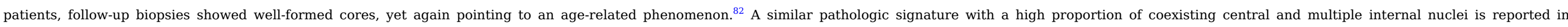

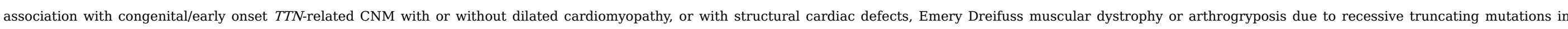

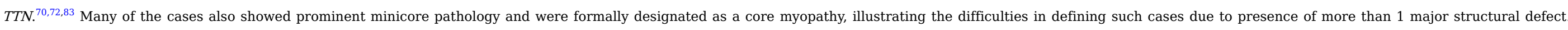

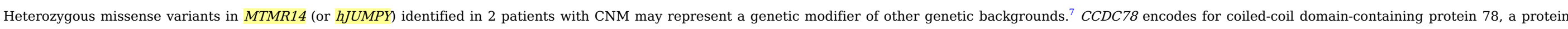

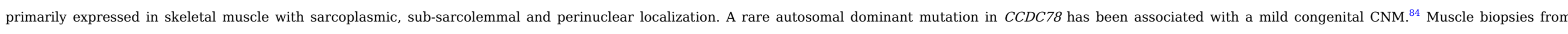

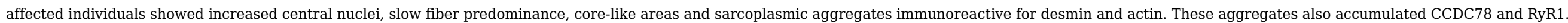

\section{Congenital Fiber Type Disproportion}

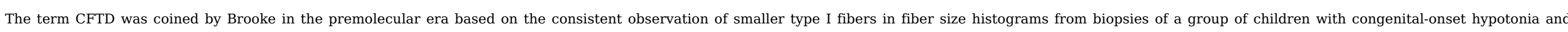

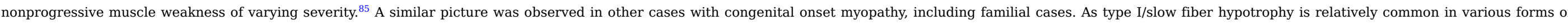

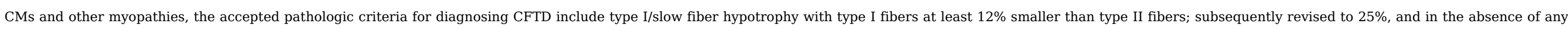




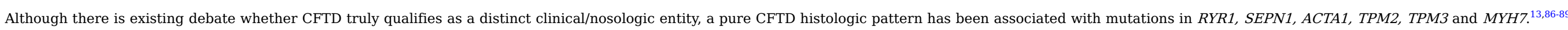

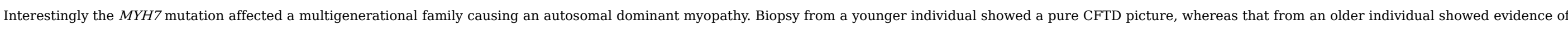

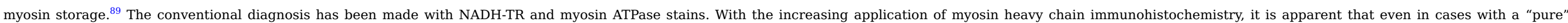

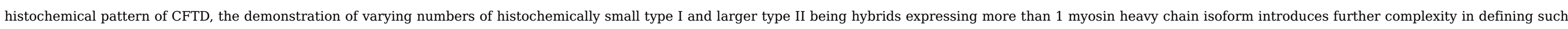
cases. Furthermore it is possible that other structural lesions associated with the CFTD genes including cores, nemaline rods, caps and other lesions may develop over time.

\section{Diagnostic Pitfalls and Differential Diagnoses}

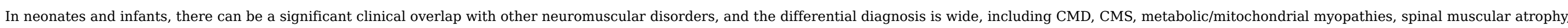

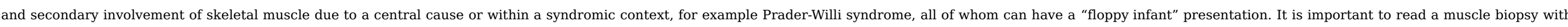

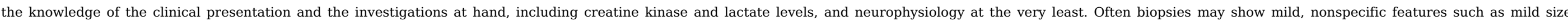

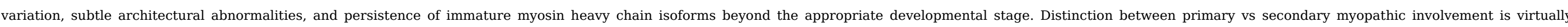

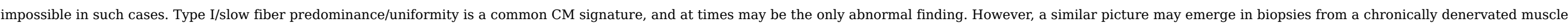

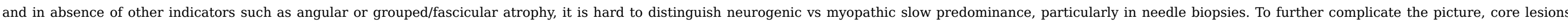

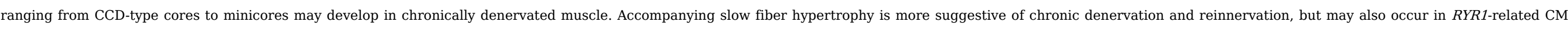

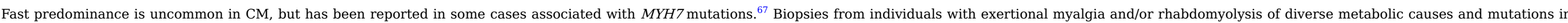

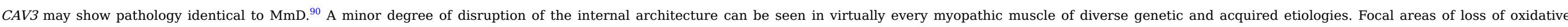

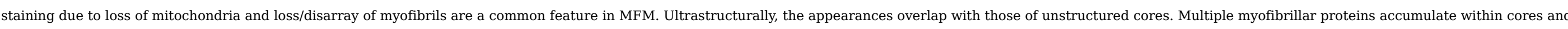

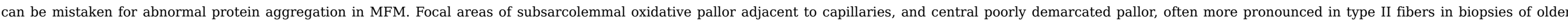

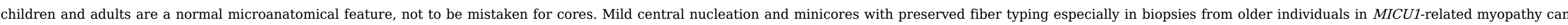

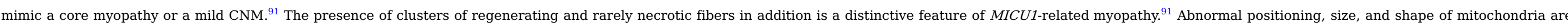

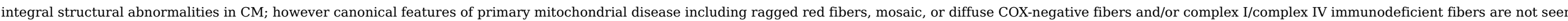

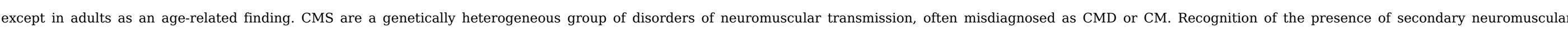

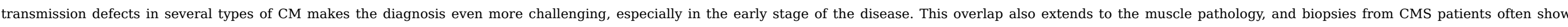

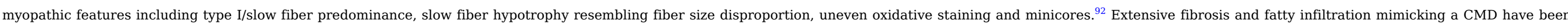

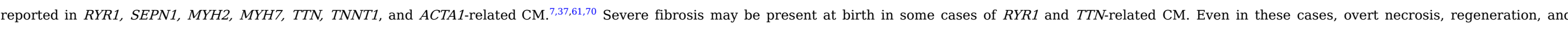

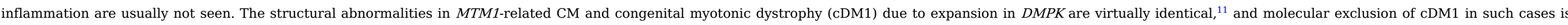

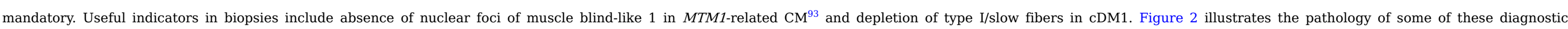
confounders. 


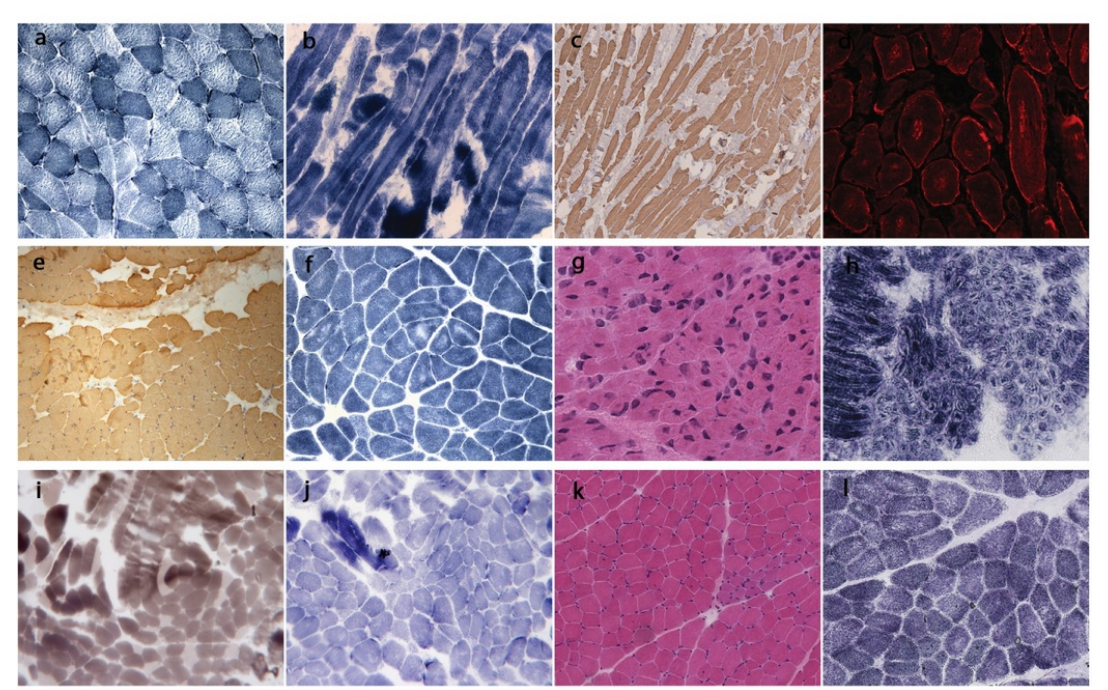

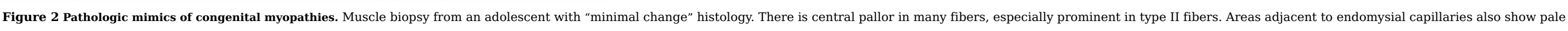

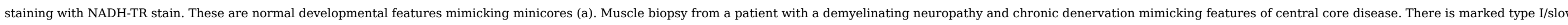

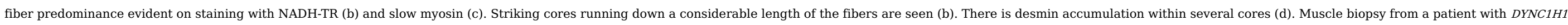

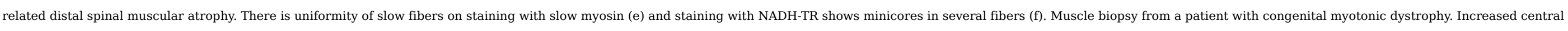

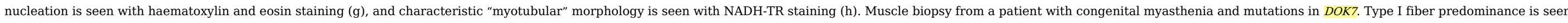

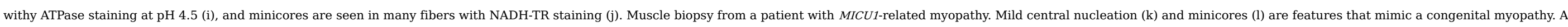
differentiating feature is the presence of clusters of basophilic regenerating fibers $(\mathrm{k})$.

\section{alt-text: Figure 2}

\section{Pathology of Emerging and Novel Congenital Myopathies}

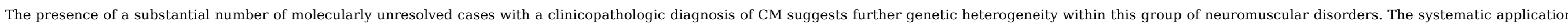

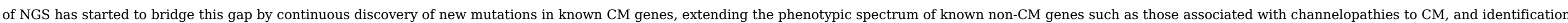

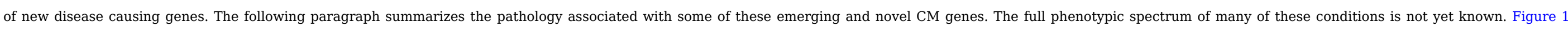
illustrates the pathology associated with some of these gene defects. (Please delete this entire last sentence in this paragraph.)

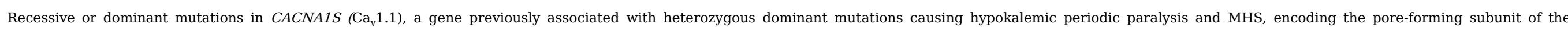

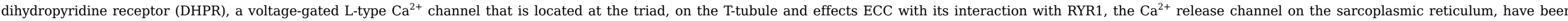

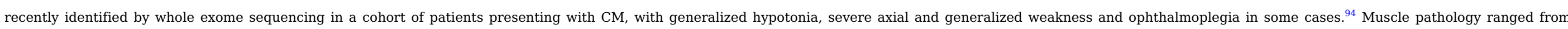

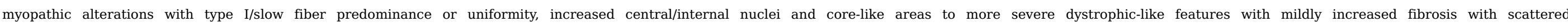

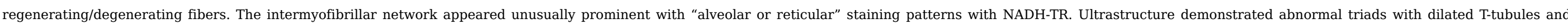

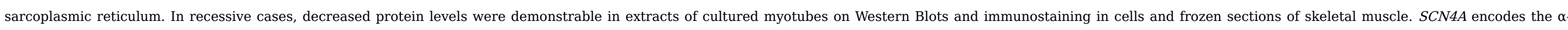

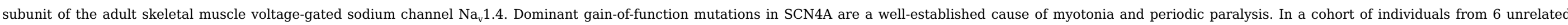

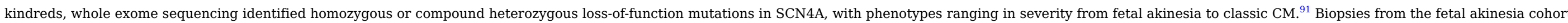

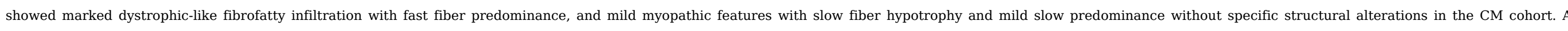

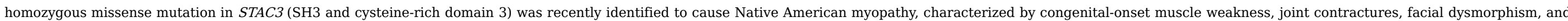




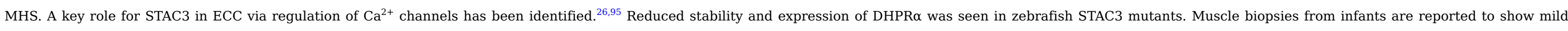

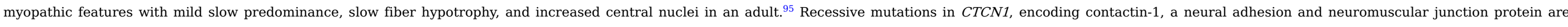

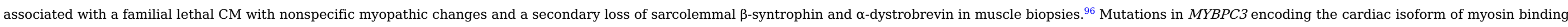

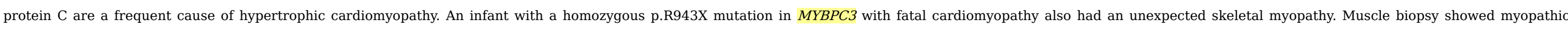

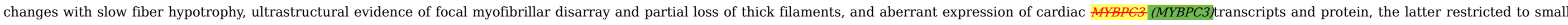

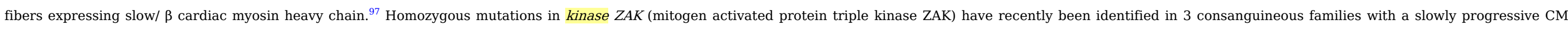

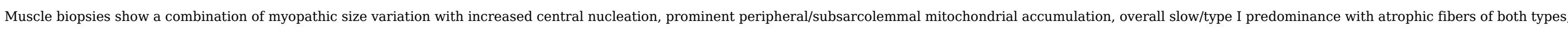

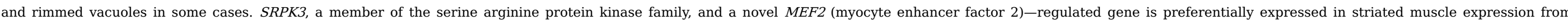

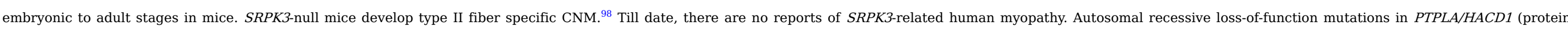

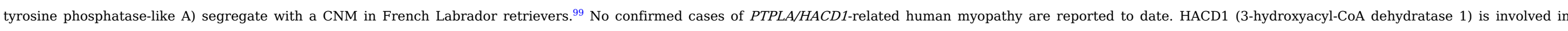

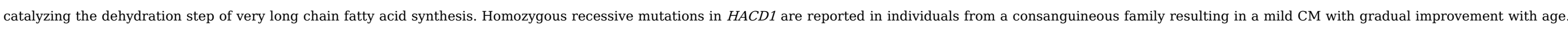
Biopsies were taken from affected individuals at a young age and showed slow fiber predominance and fiber size disproportion without cores or central nuclei. ${ }^{100}$

\section{Conclusions}

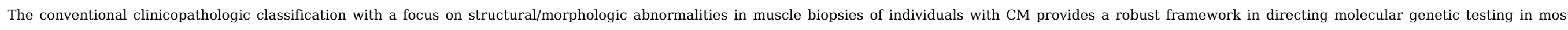

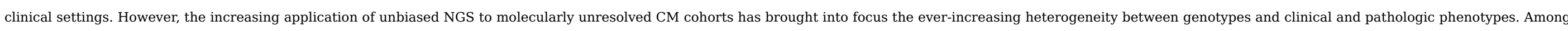

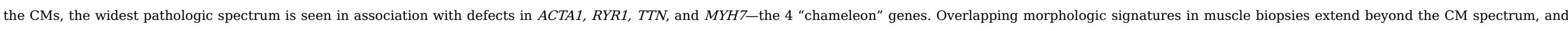

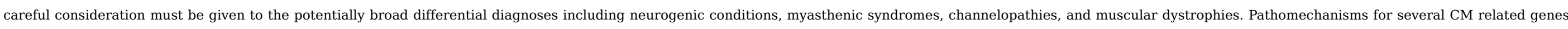

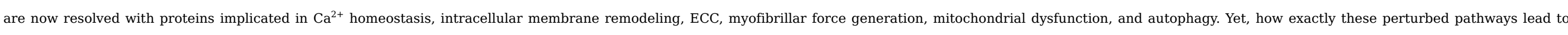

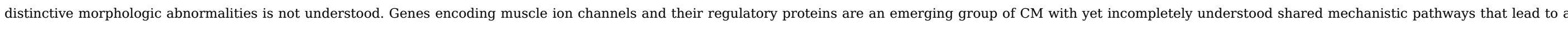

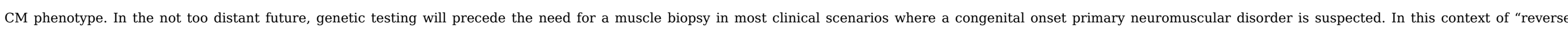

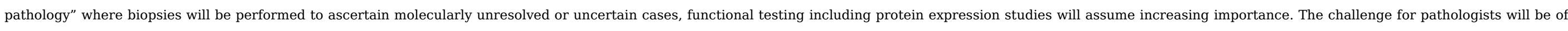
integrating these tests into the routine diagnostic pipeline.

\section{Acknowledgments}

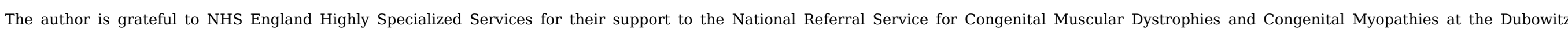

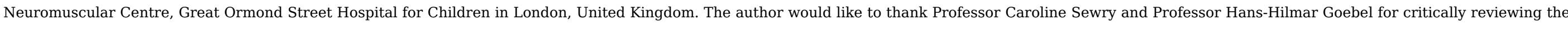
manuscript, and colleagues at the Dubowitz Neuromuscular Centre Muscle Biopsy Service in London for their technical assistance.

\section{References}

1. K.R. Magee and G.M. Shy, A new congenital non-progressive myopathy, Brain 79, 1956, 610-621.

2. V. Dubowitz and A.G. Pearse, A comparative histochemical study of oxidative enzyme and phosphorylase activity in skeletal muscle, Z Zellforch Microsk Anat Histochem 2, 1960, 105-117.

3. C. Schnell, A. Kan and K.N. North, "An artefact gone awry": Identification of the first case of nemaline myopathy by Dr R.D.K, Reye Neuromuscul Disord 10, $2000,307-312$.

4. A.J. Spiro, G.M. Shy and N.K. Gonatas, Myotubular myopathy. Persistence of fetal muscle in an adolescent boy, Arch Neurol 14, 1966, 1-14.

5. V. Dubowitz and M.H. Brooke, Muscle Biopsy: A Modern Approach, 1973, Saunders; London.

6. K.N. North, Clinical approach to the diagnosis of congenital myopathies, Semin Pediatr Neurol 18, 2011, 216-220.

7. C.A. Sewry and C. Wallgren-Pettersson, Myopathology in congenital myopathies, Neuropathol Appl Neurobiol 43, 2017, 5-23. 
8. J.K. Mah and J.T. Joseph, An overview of congenital myopathies, Continuum 22, 2016, 1932-1953.

9. H. Jungbluth, J. Ochala, S. Treves, et al., Current and future therapeutic approaches to the congenital myopathies, Semin Cell Dev Biol 64, 2017, 191-200.

10. T. Foroud, N. Pankratz, A.P. Batchman, et al., A mutation in myotilin causes spheroid body myopathy, Neurology 65, 2005, 1936-1940.

11. V. Dubowitz, C.A. Sewry, A. Oldfors, et al., Muscle Biopsy: A Practical Approach, ed 4, 2013, Saunders; Oxford, 1 online resource (xii, 572 pages).

12. R.K. Jain, S. Jayawant, W. Squier, et al., Nemaline myopathy with stiffness and hypertonia associated with an ACTA1 mutation, Neurology 78, $2012,1100-1103$.

13. K.N. North, C.H. Wang, N. Clarke, et al., Approach to the diagnosis of congenital myopathies, Neuromuscul Disord 24, 2014, 97-116.

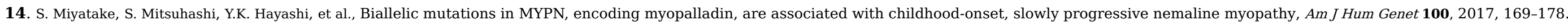

15. E. Malfatti, J. Bohm, E. Lacene, et al., A Premature stop codon in MYO18B is associated with severe nemaline myopathy with cardiomyopathy, J Neuromuscul Dis 2, 2015 , 219-227.

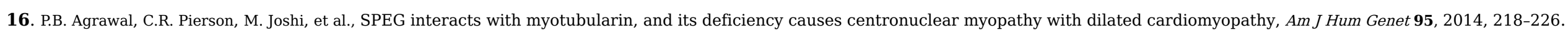

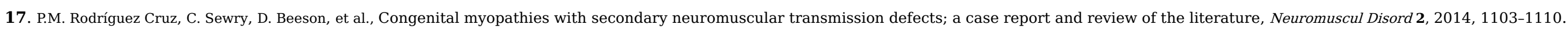

18. G. Ravenscroft, N.G. Laing and C.G. Bönnemann, Pathophysiological concepts in the congenital myopathies: blurring the boundaries, sharpening the focus, Brain 138, 2015 , $246-268$.

19. D. Carpenter, C. Ringrose, V. Leo, et al., The role of CACNA1S in predisposition to malignant hyperthermia, BMC Med Genet 10, $2009,104$.

20. J.J. Dowling, M.W. Lawlor and R.T. Dirksen, Triadopathies: An emerging class of skeletal muscle diseases, Neurotherapeutics 11, $2014,773-785$.

21. S. Treves, H. Jungbluth, F. Muntoni, et al., Congenital muscle disorders with cores: the ryanodine receptor calcium channel paradigm, Curr Opin Pharmacol 8, $2008,319-326$.

22. J.J. Dowling, A.P. Vreede, S.E. Low, et al., Loss of myotubularin function results in T-tubule disorganization in zebrafish and human myotubular myopathy, PLoS Genet 5, 2009 , e1000372.

23. A. Toussaint, B.S. Cowling, K. Hnia, et al., Defects in amphiphysin 2 (BIN1) and triads in several forms of centronuclear myopathies, Acta Neuropathol 121, 2011, 253-266.

24. E. Lee, M. Marcucci, L. Daniell, et al., Amphiphysin 2 (Bin1) and T-tubule biogenesis in muscle, Science 297, 2002, 1193-1196.

25. B.R. Nelson, F. Wu, Y. Liu, et al., Skeletal muscle-specific T-tubule protein STAC3 mediates voltage-induced Ca2+ release and contractility, Proc Natl Acad Sci USA 110, 2013, $11881-11886$.

26. E.J. Horstick, J.W. Linsley, J.J. Dowling, et al., Stac3 is a component of the excitation-contraction coupling machinery and mutated in Native American myopathy, Nat Commun 4, 2013 , 1952.

27. P.B. Stathopulos, R. Schindl, M. Fahrner, et al., STIM1/Orai1 coiled-coil interplay in the regulation of store-operated calcium entry, Nat Commun 4, 2013 , 2963.

28. S. Feske, ORAI1 and STIM1 deficiency in human and mice: roles of store-operated Ca2+ entry in the immune system and beyond, Immunol Rev 231, 2009 , 189-209.

29. A.M. Duke, P.M. Hopkins, S.C. Calaghan, et al., Store-operated Ca2+ entry in malignant hyperthermia-susceptible human skeletal muscle, J Biol Chem 285, 2010, $25645-25653$.

30. C.A. Ottenheijm and H. Granzier, New insights into the structural roles of nebulin in skeletal muscle, J Biomed Biotechnol 2010, $2010,968139$.

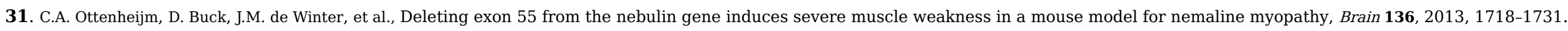

32. W.R. Telfer, D.D. Nelson, T. Waugh, et al., Neb: A zebrafish model of nemaline myopathy due to nebulin mutation, Dis Model Mech 5, 2012, 389-396.

33. G. Ravenscroft, C. Jackaman, S. Bringans, et al., Mouse models of dominant ACTA1 disease recapitulate human disease and provide insight into therapies, Brain 134, 2011 , $1101-1115$.

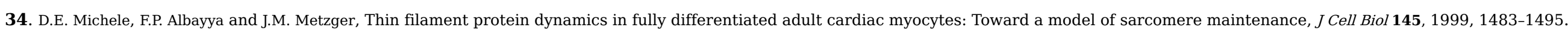

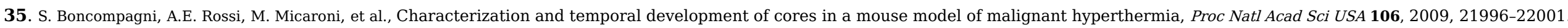


36. O. Rokach, M. Sekulic-Jablanovic, N. Voermans, et al., Epigenetic changes as a common trigger of muscle weakness in congenital myopathies, Human Mol Genet 24, 2015 , $4636-4647$.

37. K.J. Nowak, G. Ravenscroft and N.G. Laing, Skeletal muscle alpha-actin diseases (actinopathies): Pathology and mechanisms, Acta Neuropathol 125, 2013 , 19-32.

38. V.L. Lehtokari, K. Kiiski, S.A. Sandaradura, et al., Mutation update: The spectra of nebulin variants and associated myopathies, Hum Mutat 35, 2014, 1418-1426.

39. C. Wallgren-Pettersson, V.L. Lehtokari, H. Kalimo, et al., Distal myopathy caused by homozygous missense mutations in the nebulin gene, Brain 130, 2007 , $1465-1476$.

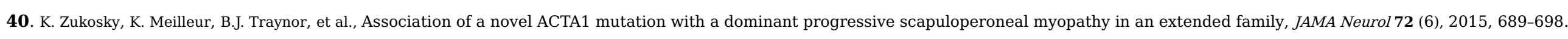

41. F. Ozer, O. Ozturk, H. Meral, et al., Camptocormia in a patient with Parkinson disease and a myopathy with nemaline rods, Am J Phys Med Rehabil 86, 2007 , 3-6.

42. L.J. Schnitzler, T. Schreckenbach, A. Nadaj-Pakleza, et al., Sporadic late-onset nemaline myopathy: Clinico-pathological characteristics and review of 76 cases, Orphanet J Rare Dis 12, 2017 , 86.

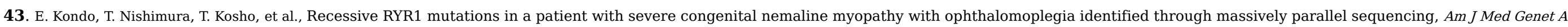
158A, 2012, 772-778.

44. M. Ohlsson, S. Quijano-Roy, N. Darin, et al., New morphologic and genetic findings in cap disease associated with beta-tropomyosin (TPM2) mutations, Neurology 71, 2008, 1896-1901.

45. L.B. Waddell, M. Kreissl, A. Kornberg, et al., Evidence for a dominant negative disease mechanism in cap myopathy due to TPM3, Neuromuscul Disord 20, 2010 , 464-466.

46. R.M. Hung, G. Yoon, C.E. Hawkins, et al., Cap myopathy caused by a mutation of the skeletal alpha-actin gene ACTA1, Neuromuscul Disord 20, 2010, 238-240.

47. S.J. Piteau, J.P. Rossiter, R.G. Smith, et al., Congenital myopathy with cap-like structures and nemaline rods: Case report and literature review, Pediatr Neurol 51, 2014 , $192-197$.

48. C.A. Sewry, J.L. Holton, D.J. Dick, et al., Zebra body myopathy is caused by a mutation in the skeletal muscle actin gene (ACTA1), Neuromuscul Disord 25, 2015, 388-391.

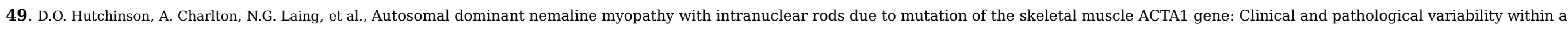
kindred, Neuromuscul Disord 16, 2006, 113-121.

50. K.J. Nowak, C.A. Sewry, C. Navarro, et al., Nemaline myopathy caused by absence of alpha-skeletal muscle actin, Ann Neurol 61, 2007, 175-184.

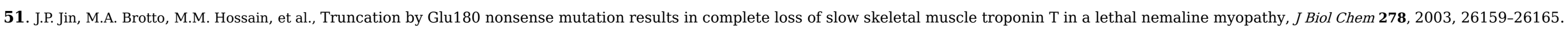
52. C.A. Sewry, S.C. Brown, K. Pelin, et al., Abnormalities in the expression of nebulin in chromosome-2 linked nemaline myopathy, Neuromuscul Disord 11, 2001 , 146-153.

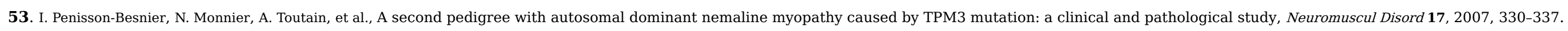

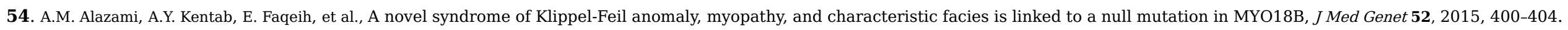

55. S. Wu, M.C. Ibarra, M.C. Malicdan, et al., Central core disease is due to RYR1 mutations in more than 90\% of patients, Brain 129, 2006, 1470-1480.

56. N.B. Romero, N. Monnier, L. Viollet, et al., Dominant and recessive central core disease associated with RYR1 mutations and fetal akinesia, Brain 126, $2003,2341-2349$.

57. C.A. Sewry, C. Müller, M. Davis, et al., The spectrum of pathology in central core disease, Neuromuscul Disord 12, 2002, 930-938.

58. I. Sato, S. Wu, M.C. Ibarra, et al., Congenital neuromuscular disease with uniform type 1 fiber and RYR1 mutation, Neurology 70, $2008,114-122$.

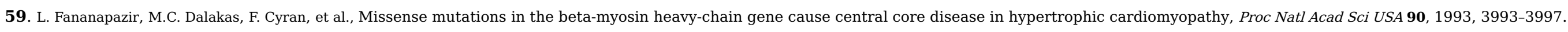

60. N. Muelas, P. Hackman, H. Luque, et al., MYH7 gene tail mutation causing myopathic profiles beyond Laing distal myopathy, Neurology 75, $2010,732-741$.

61. A. Oldfors, Hereditary myosin myopathies, Neuromuscul Disord 17, 2007, 355-367. 
62. H. Jungbluth, C.A. Sewry and F. Muntoni, Core myopathies, Semin Pediatr Neurol 18, 2011, 239-249.

63. H. Jungbluth, H. Zhou, L. Hartley, et al., Minicore myopathy with ophthalmoplegia caused by mutations in the ryanodine receptor type 1 gene, Neurology 65, $2005,1930-1935$.

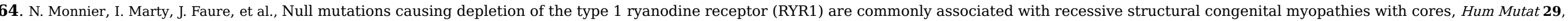
$2008,670-678$.

65. H. Zhou, H. Jungbluth, C.A. Sewry, et al., Molecular mechanisms and phenotypic variation in RYR1-related congenital myopathies, Brain 130, $2007,2024-2036$.

66. K. Amburgey, A. Bailey, J.H. Hwang, et al., Genotype-phenotype correlations in recessive RYR1-related myopathies, Orphanet J Rare Dis 8, $2013,117$.

67. P.J. Lamont, W. Wallefeld, D. Hilton-Jones, et al., Novel mutations widen the phenotypic spectrum of slow skeletal/ß-cardiac myosin (MYH7) distal myopathy, Hum Mutat 35, 2014, 868-879.

68. S.E. Boyden, L.J. Mahoney, G. Kawahara, et al., Mutations in the satellite cell gene MEGF10 cause a recessive congenital myopathy with minicores, Neurogenetics 13, 2012, 115-124.

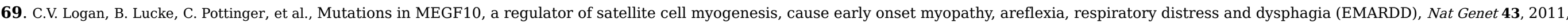
1189-1192.

70. V. Carmignac, M.A. Salih, S. Quijano-Roy, et al., C-terminal titin deletions cause a novel early-onset myopathy with fatal cardiomyopathy, Ann Neurol 61, 2007, 340-351.

71. C. Chauveau, J. Rowell and A. Ferreiro, A rising titan: TTN review and mutation update, Hum Mutat 35, 2014, 1046-1059.

72. O. Ceyhan-Birsoy, P.B. Agrawal, C. Hidalgo, et al., Recessive truncating titin gene, TTN, mutations presenting as centronuclear myopathy, Neurology 81, 2013, 1205-1214.

73. R. De Cid, R. Ben Yaou, C. Roudaut, et al., A new titinopathy: Childhood-juvenile onset Emery-Dreifuss-like phenotype without cardiomyopathy, Neurology 85, $2015,2126-2135$.

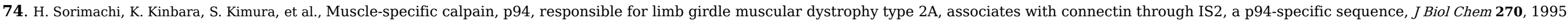
31158-31162.

75. K. Charton, J. Sarparanta, A. Vihola, et al., CAPN3-mediated processing of C-terminal titin replaced by pathological cleavage in titinopathy, Hum Mol Genet 24, 2015, 3718-3731.

76. A.M. Kaindl, F. Rüschendorf, S. Krause, et al., Missense mutations of ACTA1 cause dominant congenital myopathy with cores, J Med Genet 41, 2004 , $842-848$.

77. C. Hedberg, C. Lindberg, G. Máthé, et al., Myopathy in a woman and her daughter associated with a novel splice site MTM1 mutation, Neuromuscul Disord 22, 2012, 244-251.

78. J.A. Bevilacqua, M. Bitoun, V. Biancalana, et al., “Necklace” fibers, a new histological marker of late-onset MTM1-related centronuclear myopathy, Acta Neuropathol 117, 2009, 283-291.

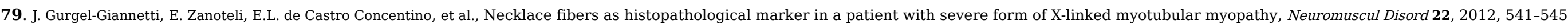

80. C.G. de Goede, A. Kelsey, H. Kingston, et al., Muscle biopsy without centrally located nuclei in a male child with mild X-linked myotubular myopathy, Dev Med Child Neurol 47, 2005 , 835-837.

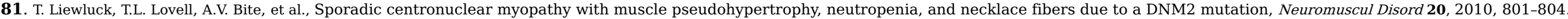

82. J.M. Wilmshurst, S. Lillis, H. Zhou, et al., RYR1 mutations are a common cause of congenital myopathies with central nuclei, Ann Neurol 68, 2010, 717-726.

83. C. Chauveau, C.G. Bonnemann, C. Julien, et al., Recessive TTN truncating mutations define novel forms of core myopathy with heart disease, Hum Mol Genet 23, 2014 , 980-991.

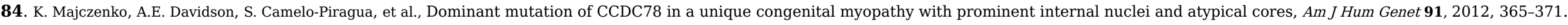

85. M.H. Brooke and W.K. Engel, The histographic analysis of human muscle biopsies with regard to fiber types. 4. Children's biopsies, Neurology 19, $1969,591-605$.

86. N.G. Laing, N.F. Clarke, D.E. Dye, et al., Actin mutations are one cause of congenital fibre type disproportion, Ann Neurol 56, 2004, 689-694.

87. N.F. Clarke, L.B. Waddell, S.T. Cooper, et al., Recessive mutations in RYR1 are a common cause of congenital fiber type disproportion, Hum Mutat 31, 2010, E1544-E1550. 
88. A. Brandis, E. Aronica and H.H. Goebel, TPM2 mutation, Neuromuscul Disord 18, 2008, 1005.

89. S. Ortolano, R. Tarrio, P. Blanco-Arias, et al., A novel MYH7 mutation links congenital fiber type disproportion and myosin storage myopathy, Neuromuscul Disord 21, 2011 , $254-262$.

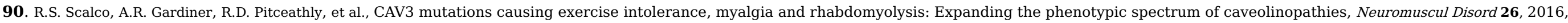
504-510.

91. I.T. Zaharieva, M.G. Thor, E.C. Oates, et al., Loss-of-function mutations in SCN4A cause severe foetal hypokinesia or "classical" congenital myopathy, Brain 139, $2016,674-691$.

92. M. Kinali, D. Beeson, M.C. Pitt, et al., Congenital myasthenic syndromes in childhood: Diagnostic and management challenges, J Neuroimmunol 201-202, $2008,6-12$.

93. I. Holt, V. Jacquemin, M. Fardaei, et al., Muscleblind-like proteins: Similarities and differences in normal and myotonic dystrophy muscle, AmJ Pathol 174, 2009 , $216-227$.

94. V. Schartner, N.B. Romero, S. Donkervoort, et al., Dihydropyridine receptor (DHPR, CACNA1S) congenital myopathy, Acta Neuropathol 133, $2017,517-533$.

95. J.W. Linsley, I.U. Hsu, L. Groom, et al., Congenital myopathy results from misregulation of a muscle Ca2+ channel by mutant Stac3, Proc Natl Acad Sci USA 114 (2), 2017, E228-E236.

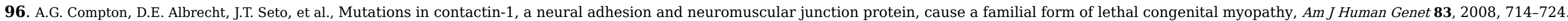

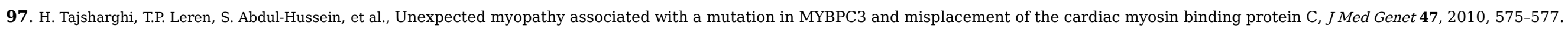

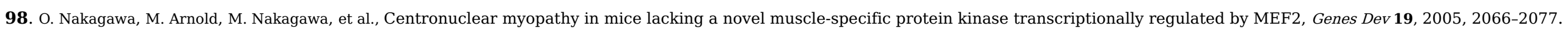

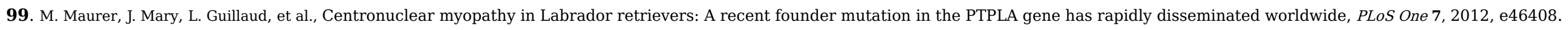

100. E. Muhammad, O. Reish, Y. Ohno, et al., Congenital myopathy is caused by mutation of HACD1, Hum Mol Genet 22, 2013, 5229-5236.

\section{Queries and Answers}

Query: Please confirm that givennames and surnames have been identified correctly.

Answer: Yes

Query: Please check the short title inserted by the copyeditor for correctness.

Answer: Please change the short title from $\mathrm{CMs}$ to $\mathrm{CM}$ 